of globe perforation inherent in sharp-needle intraconal injection (although this was not encountered in Southampton). Clearly we make great efficiency savings by being less reliant on anaesthetic cover, especially when providing theatre time for acute surgical VR work.

The paper goes on to state that $51.7 \%$ of the cases included in the study are 'retinopexy + / - vitrectomy'. This could be interpreted as a significant proportion in the LA group simply receiving retinopexy for retinal tear.

Clarification on the above will be welcomed.

C Goldsmith, T McMullan and R Burton

Norfolk and Norwich University Hospital, Norwich, Norfolk NR4 7UU, UK

Correspondence: C Goldsmith, Norfolk and Norwich University Hospital, Flat 1, Bulman House, Colney Lane, Norwich, Norfolk NE4 7UU,

UK

Tel: +441603 288511;

E-mail: cgldsmith@yahoo.co.uk

Eye (2006) 20, 1104-1105. doi:10.1038/sj.eye.6702142; published online 6 January 2006

Sir,

\section{Response to Goldsmith et al}

We were interested in Goldsmith et al's comments on our recent paper. ${ }^{1}$ We are aware that subtenons anaesthesia is used for VR surgery; ${ }^{2}$ however, to achieve a rate of $87 \%$, under local anaesthesia, is certainly impressive. The authors are not clear on their own use of sedation. In some units nearly all patients are sedated, and in others it is rarely used. We have tailored our use to measured patient satisfaction outcomes performed over the last 5 years, ${ }^{3-4}$ and clearly have a lower threshold for their use than Goldsmith et al. This may be because we have access to an experienced anaesthetist for our VR lists.

The Royal College of Ophthalmologists 2004 guidelines on cataract surgery do not specify the necessity of anaesthetist presence where blunt needle subtenons anaesthesia is required, such anaesthetic cover is recommended where sharp needle anaesthesia and/or sedation is required. ${ }^{5}$ Arguably in VR surgery anaesthetic cover is more important given the longer and more unpredictable nature of the surgery.

We note with interest Goldsmith et al's comment that grouping all retinopexy patients may bias the results. However, our previous work showed that the laser and cryopexy were more important determinants of discomfort during vitrectomy than other aspects of the surgery, and so these were analysed as one group. ${ }^{2}$

\section{References}

1 Costen MT, Newsom RS, Wainwright AC, Luff AJ, Canning $\mathrm{CR}$. Expanding role of local anaesthesia in vitreoretinal surgery. Eye 2005; 19(7): 755-761.

2 Bourke RD, Dowler JG, Heyworth P, Cooling RJ, Moore C. Extraconal bupivacaine in scleral buckling procedures. Retina 1996; 16(3): 240-245.

3 Newsom RS, Wainwright AC, Canning CR. Local anaesthesia for 1221 vitreoretinal procedures. Br J Ophthalmol 2001; 85(2) 225-227.

4 Knight HM, Newsom RB, Canning CR, Luff AJ, Wainwright AC. Local anaesthesia for vitreoretinal surgery: an audit of patient and surgical experience. Eur J Ophthalmol 2001; 11(4): 366-371.

5 Royal College of Ophthalmologists. Guidelines for Cataract Surgery 2004

MTJ Costen, RSB Newsom, AC Wainwright,

AJ Luff and CR Canning

Hull \& East Yorkshire Eye Hospital,

Fountain Street, Anlaby Road,

Hull HU3 2JZ, UK

Correspondence: MTJ Costen,

Hull \& East Yorkshire Eye Hospital,

Fountain Street,

Anlaby Road, Hull,

HU3 2JZ, UK

Tel: + 441482 605326;

Fax: + 441482604362

E-mail: mtcosten@doctors.org.uk

Eye (2006) 20, 1105. doi:10.1038/sj.eye.6702143;

published online 18 November 2005

Sir,

The urgency and site of retinal detachment surgery

Four letters in the correspondence section of The Journal prompt me to join the debate about the setting in which retinal detachment surgery is undertaken, both with respect to urgency and surgical facility. ${ }^{1-4}$ This is an ongoing debate and has been discussed in This Journal before. ${ }^{5}$

The first fallacy that needs to be highlighted is about the urgency of management of macula-on detachments. Although it is taken for granted that all macula-on detachments should be operated on within hours of 